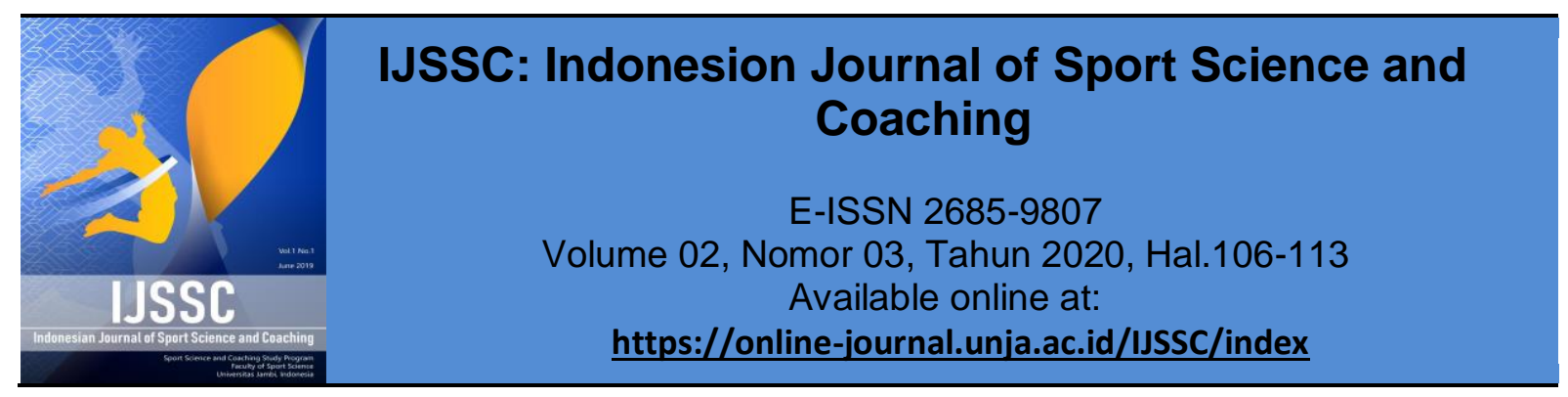

Research Article OPEN ACCESS

\title{
Pengembangan Model Pembelajaran Gerak Dasar Nomor Lompat Berbasis Permainan Tradisional di Sekolah Dasar
}

\author{
(Development of Basic Motion Learning Models Based on Traditional Games in Primary Schools)
}

\author{
Roni Zakaria Shaputra, Rostika Flora, Sukirno
}

Fakultas Keguruan dan IImu Pendidikan, Universitas Sriwijaya

JI. Raya Palembang-Prabumulih, Indralaya, Ogan Ilir, Sumatera Selatan 30662, Indonesia

*Corresponding author. ronizakariashaputra@yahoo.com

\begin{tabular}{|c|c|}
\hline Informasi Artikel & ABSTRACT \\
\hline $\begin{array}{l}\text { Submit: } 11-09-2020 \\
\text { Diterima: } 30-10-2020 \\
\text { Dipublikasikan: } 08-11-2020\end{array}$ & $\begin{array}{l}\text { This study aims to develop a basic motion learning model jumping numbers } \\
\text { based on traditional games in elementary schools. The method in this study is a } \\
\text { method of development with procedures in research, namely: (1) Requirement } \\
\text { analysis, (2) Initial model, (3) Validation of the initial model, (4) Description of } \\
\text { expert validation data, (5) Revision of the initial model draft, ( } 6 \text { ) Small group } \\
\text { outcome data, (7) Revision of the model after the small group trial, (8) Large } \\
\text { group outcome data, (9) Model revision after the large group trial. This research } \\
\text { was conducted at SDN } 02 \text { Sungai Pinang. In this study, the results of } \\
\text { questionnaire questionnaire validation obtained from expert validators namely } \\
\text { the physical education teacher on the draft product model of jump-based } \\
\text { learning numbers on average game } 3.8 \text { so that it is included in the valid } \\
\text { category. The results of student motivation questionnaire analysis obtained a } \\
\text { percentage of } 86.4 \% \text { while the t-test results obtained were } 12,387 \text { with ttable } \\
3.24 \text { then tcount }=12.387>\text { ttable } 3.24 \text { as well as the results of the validation of } \\
\text { psychomotoric results of students in both } 64 \% \text { categories, and } 32 \% \text { categories } \\
\text { very good, obtained tcount of } 15.601 \text { with ttable } 2.667 \text { which is stated tcount> } \\
\text { ttable. So it can be concluded that the new learning model or game-based } \\
\text { Jump learning model given to students is valid, practical, and effective to make } \\
\text { students motivated to learn jump-based games and actively move in learning } \\
\text { and can already be used in the game-based jump learning process in Primary } \\
\text { Schools ( SD). } \\
\text { Key words: development, learning models, jumping, game based. }\end{array}$ \\
\hline Penerbit & $\begin{array}{l}\text { Rey woras: development, learning models, jumping, game dased. } \\
\text { ABSTRAK }\end{array}$ \\
\hline $\begin{array}{l}\text { Program Studi Pendidikan Biologi } \\
\text { FKIP Universitas Jambi, } \\
\text { Jambi- Indonesia }\end{array}$ & $\begin{array}{l}\text { Penelitian ini bertujuan untuk mengembangkan model pembelajaran gerak } \\
\text { dasar nomor lompat berbasis permainan tradisional di sekolah dasar. Metode } \\
\text { dalam penelitian ini adalah metode pengembangan dengan prosedur dalam } \\
\text { penelitian, yaitu : (1) Analisis kebutuhan, (2) Model awal, (3) Validasi model } \\
\text { awal, (4) Deskripsi data validasi ahli, (5) Revisi draft model awal, (6) Data hasil } \\
\text { kelompok kecil, (7) Revisi model setelah uji coba kelompok kecil, (8) Data hasil } \\
\text { kelompok besar, (9) Revisi model setelah uji coba kelompok besar. Penelitian } \\
\text { ini dilakukan di SDN 02 Sungai Pinang. Pada penelitian ini didapatkan hasil } \\
\text { validasi angket kuisioner dari validator ahli yaitu guru penjaskes pada draf } \\
\text { produk model pembelajaran nomor lompat berbasis permainan rata-rata 3,8 }\end{array}$ \\
\hline
\end{tabular}


sehingga sudah masuk dalam kategori valid. Hasil analisis kuisioner motivasi siswa didapat persentase sebesar $86,4 \%$ sedangkan hasil $t$-test yang didapat adalah 12.387 dengan tabel $=3,24$ maka thitung $=12.387>t_{\text {tabel }} 3,24$ serta hasil validasi hasil psikomotorik siswa kategori baik $64 \%$, dan $32 \%$ kategori sangat baik, didapatkan thitung sebesar 15,601 dengan tabel 2,667 yang dinyatakan

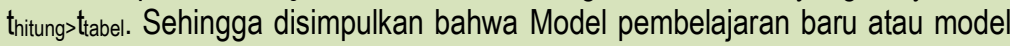
pembelajaran Lompat berbasis permainan yang diberikan pada siswa valid, praktis, dan efektif untuk membuat siswa termotivasi untuk belajar lompat berbasis permainan serta aktif bergerak dalam pembelajaran dan sudah bisa digunakan dalam proses pembelajaran lompat berbasis permainan di Sekolah Dasar.

Kata kunci: pengembangan, model pembelajaran, lompat, berbasis permainan.

\section{PENDAHULUAN}

Pendidikan jasmani adalah bagian integral dari pendidikan anak secara keseluruhan dan tujuannya harus sesuai dengan tujuan pendidikan (Harjarati, 2019). Hal ini merujuk pendapat (Indrayana, 2017; Usra, 2012) pendidikan jasmani dapat memberikan sumbangan bagi pembinaan karakter agar taat pada penegakan hukum, karena dalam penyelenggaraan pendidikan jasmani dan sebagai anggota tim olah raga peserta didik harus mentaati aturan main, dan atlet yang baik akan mampu untuk mengontrol dorongan dan menundukkan keinginan yang akan merugikan kelompok. Menurut Lutan dalam (Suprayitno, 2014) Pendidikan Jasmani mengandung potensi yang besar untuk memberikan sumbangan kepada pertumbuhan dan perkembangan anak secara menyeluruh. Pada sekolah dasar pendidikan jasmani diajarkan dari kelas satu sampai dengan kelas enam.

Lompat termasuk dalam gerak dasar pada kurikulum sekolah dasar yang dipelajari di kelas lima sekolah dasar, lompat pada umumnya siswa tingkat sekolah dasar belum mempelajari nomor lompat untuk prestasi, melainkan hanya mempelajari gerak dasar dari lompat. Menurut Ariawan dalam (Suharnoko \& Firmansyah, 2018) Lompat atau loncat adalah suatu rangkaian gerakan untuk mengangkat tubuh ke atas melalui beberapa proses yaitu lari, tumpuan, melayang dan mendarat. Kenyataan pembelajaran gerak dasar nomor lompat di sekolah dasar terdapat beberapa kendala yang dihadapi diantaranya:

Tabel 1 Data hasil Observasi

\begin{tabular}{lll}
\hline No. & \multicolumn{1}{c}{ Guru } & \multicolumn{1}{c}{ Siswa } \\
\hline 1. & Kurangnya variasi dalam mengajar. & Pembelajaran kurang diminati oleh peserta didik. \\
& & Peserta didik memiliki antusias yang rendah \\
2 & Guru dalam mengajar sangat subjektif. & dalam belajar. \\
& & Peserta didik cepat bosan dalam belajar. \\
\hline
\end{tabular}

Berdasarkan penjelasan di atas, peneliti ingin melakukan mengembangkan suatu model yang dapat memberikan solusi atas permasalahan yang di dapat. Permasalahan yang ditemukan membuat peneliti kemudian melakukan wawancara 
dengan guru penjaskes untuk mencari tahu mengenai proses pembelajaran yang dilaksanakan selama ini. Dari hasil wawancara didapatkan pembelajaran penjaskes gerak dasar nomor lompat masih terbatas karena kurang tepatnya model atau metode pembelajaran melalui permainan yang digunakan oleh guru yang bersangkutan, faktor pendukung lain yang mengakibatkan keaktifan siswa dalam belajar olahraga adalah penyampaian materi yang dilakukan guru masih menggunakan model atau metode demonstrasi saja tanpa didukung model atau metode yang lain dan juga lapangan atau sarana masih kurang memadai di sekolah. Menurut peneliti ini merupakan tantangan bagi para guru penjaskes agar dalam melaksanakan proses pembelajaran selalu mengembangkan sikap kreatif dan inovatif agar proses pembelajaran dapat berjalan dengan lancar dan siswa merasa puas serta menyenangkan. Hal inilah yang mungkin mempengaruhi kurang aktifnya siswa pada pembelajaran gerak dasar nomor lompat yang ada di SD sesuai dengan hasil observasi yang telah dilakukan.

Abdul Alim yang dikutip oleh (Burhaein, 2017)), karakteristik anak usia Sekolah Dasar berkaitan dengan aktivitas fisik yaitu umumnya anak senang bermain, senang bergerak, senang bekerja dalam kelompok dan senang praktik langsung. Berdasarkan penjelasan tersebut, peneliti memiliki rencana untuk mengembangkan model pembelajaran melalui model permainan (belajar sambil bermain) pada saat jam pelajaran penjaskes gerak dasar nomor lompat. Menurut (Ardiyanto et al., 2014) bermain memberikan kesempatan pada anak untuk mengekspresikan dorongandorongan kreatifnya sebagai kesempatan untuk merasakan objek-objek dan tantangan untuk menemukan sesuatu dengan cara-cara baru, untuk menemukan penggunaan suatu hal secara berbeda, menemukan hubungan yang baru antara sesuatu dengan sesuatu yang lain serta mengartikannya dalam banyak alternatif cara.

Gerak dasar lompat dapat dilakukan sambil bermain, atau melalui bentukbentuk permainan dengan harapan siswa dapat terangsang untuk melakukan. Karakteristik yang perlu diperhatikan pada siswa SD, yaitu: senang bermain, senang bergerak, siswa senang bekerja dalam kelompok, dan senang merasakan atau melakukan sesuatu secara langsung. Karena kreativitas bermain merupakan dunia siswa SD dan sangat menyenangkan. Berdasarkan uraian di atas, maka peneliti tertarik untuk melaksanakan kegiatan penelitian dengan judul "Pengembangan Model Pembelajaran Gerak Dasar Nomor Lompat Berbasis Permainan Tradisional di Sekolah Dasar".

\section{METODE PENELITIAN}

Jenis penelitian ini adalah penelitian pengembangan atau development research. Adapun langkah-langkah penelitian pengembangan meliputi: analisis kebutuhan, model awal, validasi desain awal, deskripsi validasi ahli, revisi desain awal, uji coba model, revisi model, uji coba pemakaian, revisi model dan produk akhir. 


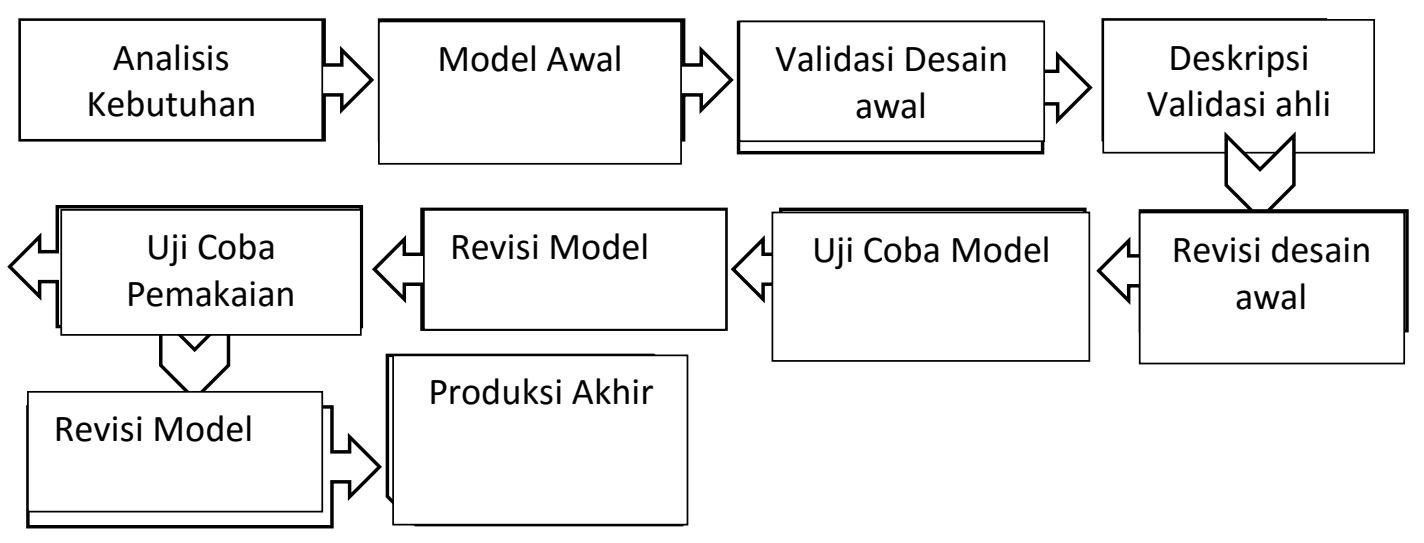

Gambar 1. Desain Penelitian Pengembangan (Sugiyono, 2017:37)

Prosedur dalam penelitian ini menurut (Sugiyono, 2017), yaitu : (1) Analisis kebutuhan, (2) Model awal, (3) Validasi model awal, (4) Deskripsi data validasi ahli, (5) Revisi draft model awal, (6) Data hasil kelompok kecil, (7) Revisi model setelah uji coba kelompok kecil, (8) Data hasil kelompok besar, (9) Revisi model setelah uji coba kelompok besar.

Supaya pengembangan model pembelajaran yang lebih efektif, efesien dan valid yang dapat diterima oleh semua pihak yang bersangkutan didalam penelitian ini. Subjek penelitiaan ini terdiri dari siswa berbeda-beda karakter dengan jumlah 25 siswa pada uji coba kelompok kecil dan 50 siswa pada uji coba kelompok besar, kemudian diberikan perlakukan meliputi aspek kebutuhan, dalam hal ini produk di uji coba diadakan pretest dan posttest serta pemberian angket diisi oleh siswa

Dalam penelitian ini pengumpulan data dilakukan dengan beberapa cara. Pertama observasi menggunakan lembar observasi yang terdapat di buku guru Penjaskes. Observasi dilakukan selama proses pembelajaran untuk melihat aspek motivasi siswa. Kedua wawancara, menurut (Moleong, 2011) dilakukan oleh dua pihak, yaitu pewawancara (interviever) yang mengajukan pertanyaan dan terwawancara (interviewee) yang memberikan jawaban atas pertanyaan itu. Pada penelitian ini penulis mewawancarai guru Penjaskes. Wawancara dilakukan untuk mendapatkan data tentang permainan lompat, model pembelajaran, pendekatan pembelajaran dan keaktifan siswa selama proses pembelajaran Penjaskes pada siswa SD Maitreyawira Palembang dan Sekolah dasar Negeri 02 Sungai Pinang. Pada penelitian ini wawancara yang dilakukan adalah wawancara terstruktur/tertutup.

Teknik pengumpulan data ketiga adalah angket. Pada penelitian ini angket diberikan kepada siswa sebagai pengguna model yang bertujuan untuk memperoleh informasi mengenai efektifitas model yang diujikan selama proses pembelajaran Penjaskes. Keempat, pengumpulan data untuk menghitung kemampuan psikomotorik adalah dengan melakukan tes. Tes merupakan himpunan pertanyaan yang harus dijawab, harus ditanggapi, atau tugas yang harus dilaksanakan oleh orang yang dites (Jihad \& Haris, 2012). 
Analisis wawancara dilakukan dengan cara mendeskripsikan pendapat guru tentang kebutuhan pengembangan model pembelajaran semester genap. Data hasil angket yang diperoleh dari pengguna model pembelajaran, kemudian dianalisis menggunakan skala linkert. Angket/kuisioner yang digunakan untuk ahli berupa sejumlah aspek yang harus dinilai kelayakan model yang dikembangkan. Angket/kuesioner motivasi yang diberikan kepada siswa berupa 10 jumlah pertanyaan, yang harus dijawab oleh siswa dengan alternatif jawaban "ya" atau "tidak" dengan mengunakan skala Guttman. Hasil tes yang didapatkan pada uji kelompok kecil dan kelompok besar kemudian dilakukan pengujian statistik $t$-paired test.

\section{HASIL PENELITIAN DAN PEMBAHASAN}

Guru harus memiliki strategi agar siswa dapat belajar secara efektif dan efisien (Saifullah, 2010). Salah satu faktor yang akan menunjang keberhasilan proses belajar mengajar di kelas adalah ketepatan model pembelajaran yang digunakan oleh guru. Indrawati dalam kutipan (Ripai \& Nana Sutarna, 2019) juga menyebutkan bahwa secara umum model pembelajaran berfungsi untuk membantu dan membimbing guru untuk memilih komponen proses dalam pembelajaran teknik, strategi, dan metode pembelajaran agar tujuan pembelajaran tercapai.Model pembelajaran dapat dijadikan pola pilihan, artinya para guru boleh memilih model pembelajaran yang sesuai untuk mencapai tujuan pendidikannya.

Play is intrinsically motivated. it is an end in it self, done only for the satisfaction of doing it. a related characteristic of play is that it must be freely chosen by the participants. (Hughes, 2010) Bermain dapat digunakan sebagai media untuk meningkatkan keterampilan, mengembangkan kompetensi dalam usaha mengatasi dunianya dan mampu mengembangkan kreativitas. Tujuan pendidikan jasmani yang teratur untuk menciptakan lingkungan yang mendorong pengalaman pergerakan pilihan menghasilkan reaksi yang diinginkan yang berperan untuk perkembangan individu dalam semua tahap kehidupan (Hartati, 2016)

Hasil kegiatan pre test terdapat 25 siswa dalam pengisian angket didapatkan persentase sebesar $44,4 \%$ untuk pre-test dengan kategori Cukup sedangkan pada kegiatan post test terdapat 25 siswa dalam pengisian angket didapatkan persentase sebesar dan $84,4 \%$ untuk post-test dengan kategori Baik, sedangkan hasil $t$-test yang didapat adalah 27,224 dengan $t_{\text {tabel }}=2,48$ maka $t_{\text {hitung }}=27,224>t_{\text {tabel }} 2,48$ Dengan demikian ada peningkatan pada komponen psikomotorik siswa dalam pembelajaran lompat berbasis permainan dengan taraf signifikan 0.05 , dengan kata lain hipotesis $(\mathrm{Ho})$ ditolak, karena ada perbedaan yang signifikan, yakni Data kesimpulan jika nilai signifikan $>0,05$ maka $\mathrm{H}_{0}$ diterima dan jika nilai signifikan $<0,05$ maka $\mathrm{H}_{0}$ ditolak (Sugiyono, 2014).

Berdasarkan hasil angket kuisoner didapat persentase dengan rata-rata nilai $86,4 \%$ dengan kategori Baik, maka hasil tersebut menunjukan pengembangan model pembelajaran lompat berbasis permainan selama digunakan oleh 50 siswa pada uji coba kelompok besar teruji akan kevalidannya. Berdasarkan data yang 
diperoleh dari nilai sebelum dan nilai sesudah didapatkan rata-rata nilai sebelum yaitu $42 \%$ dan nilai sesudah $86,4 \%$ kemudian di hitung untuk memperoleh perbedaan model pembelajaran lama dan model pembelajaran baru.

Hasil peningkatan motivasi siswa dari $42 \%-86,4 \%$ ini membuktikan bahwa pendapat Abdul Alim yag dikutip oleh (Burhaein, 2017) karakteristik anak usia Sekolah Dasar berkaitan dengan aktivitas fisik yaitu umumnya anak senang bermain, senang bergerak, senang bekerja dalam kelompok dan senang praktik langsung Serta pendapat Rogers dan Sawyers dikutip jurnal (Andriani, 2012) bahwa permainan adalah sebuah sarana yang dapat mengembangkan anak secara optimal dan juga berfungsi sebagai kekuatan, pengaruh terhadap perkembangan dan lewat permainan pula didapat pengalaman yang penting dalam dunia anak. Menurut Husdarta dalam (Hasbillah, 2020) Bermain pada intinya adalah aktivitas yang digunakan sebagai hiburan. Bermain adalah aktivitas yang digunakan untuk mendapatkan kesenangan, keriangan, atau kebahagiaan (Rosdiani, 2012; Wibowo \& Indrayana, 2019). Sehingga model pembelajaran yang dikembangkan dengan memasukan unsur permainan didalamnya membuat siswa bersemangat, antusias terhadap pembelajaran, serta mengikuti proses pembelajaran dengan senang, hal ini juga berdapak pada kemampuan psikomotorik siswa.

Berdasarkan pembelajaran yang berlangsung tidak terjadi hambatan dan hasil perhitungan data yang diperoleh sebagai berikut: hasil kegiatan pre test terdapat 50 siswa dalam pengisian angket didapatkan persentase sebesar $42 \%$ dengan kategori Cukup sedangkan pada kegiatan post test terdapat 50 siswa dalam pengisian angket didapatkan persentase sebesar $86,4 \%$ dengan kategori Baik, sedangkan hasil $t$-test yang didapat adalah 12.387 dengan $t_{\text {tabel }}=3,24$ maka $t_{\text {hitung }}=12.387>t_{\text {tabel }} 3,24$ Dengan demikian ada peningkatan pada komponen motivasi siswa dalam pembelajaran lompat berbasis permainan dengan taraf signifikan 0.05 , dengan kata lain hipotesis $(\mathrm{Ho})$ ditolak, karena ada perbedaan yang signifikan, yakni Data kesimpulan jika nilai signifikan $>0,05$ maka $\mathrm{H}_{0}$ diterima dan jika nilai signifikan $<0,05$ maka $\mathrm{H}_{0}$ ditolak (Sugiyono, 2017)

\section{KESIMPULAN}

Berdasarkan data yang diperoleh dari penelitian ini diperoleh rancangan pengembangan model pembelajaran nomor lompat berbasis permainan di Sekolah Dasar dinyatakan valid dan praktis dengan validasi yang diisi oleh validator tersebut didapatkan nilai rata-rata 3,8 . Serta didapat hasil validasi kefektifan pada tahap small group mengenai kualitas model pembelajaran didapatkan nilai rata-rata 3,85 sedangkan hasil $t$-test yang didapat adalah 27,224 dengan $t_{\text {tabel }}=2,48$ maka $t_{\text {hitung }}=$ $27,224>t_{\text {tabel }} 2,48$. Pada uji validasi dari kelompok besar didapatkan hasil thitung sebesar 12.387 dengan $t_{\text {tabel }}=3,24$ maka $t_{\text {hitung }}=12.387>t_{\text {tabel }} 3,24$ sehingga disimpulkan bahwa model pembelajaran yang dikembangkan berpengaruh dalam peningkatan kemampuan peserta didik dalam aktivitas atletik turbo atau lempar. Pada penilaian motivasi didapatkan hasil $82 \%$ layak pada kelompok kecil dan $84,8 \%$ layak pada kelompok besar saat melakukan uji guttman untuk hasil angket yang 
diberikan kepada peserta didik sehingga dinyatakan efektif meningkatkan motivasi siwa .

\section{UCAPAN TERIMA KASIH}

Ungkapan rasa terima kasih kepada Ibu Dr. Rostika Flora, S. Kep., M. Kes., AIFO dan Bapak Dr. Sukirno sebagai Pembimbing Penelitian ini. Serta Bapak Dr. lyakrus, M.Kes sebagai penguji I dan Dr. Meirizal Usra, M.Kes sebagai penguji II yang telah banyak memberi masukan dan bimbingan meluangkan waktunya dalam penyelesaian tesis ini.

\section{DAFTAR PUSTAKA}

Andriani, T. (2012). Permainan Tradisional Dalam Membentuk Karakter Anak Usia Dini Oleh : Tuti Andriani Dosen Fakultas Tarbiyah dan Keguruan Universitas Islam Negeri Sultan Syarif Kasim Riau. Sosial Budaya, 9(1), 121-136.

Ardiyanto, A., Sukoco, P., \& Yogyakarta, U. N. (2014). Pengembangan Model

Pembelajaran Berbasis Permainan Tradisional. Keolahragaan, 2(1), 119-129.

Burhaein, E. (2017). Aktivitas Fisik Olaharaga untuk Pertumbuhan dan

Perkembangan Siswa SD. Indonesian Journal of Primary Education, 1, 51-58.

Harjarati, H. (2019). Memberdayakan olah raga nasional. Jurnal Pelangi IImu, 2(5), 204-220.

Hartati. (2016). Manajemen Pendidikan Jasmani dan Olahraga. Amanah Offset.

Hasbillah, M. (2020). Upaya Meningkatkan Hasil Belajar Lompat Jauh Melalui

Pendekatan Bermain Murid Kelas V SD Negeri 375 Tancung Kabupaten Wajo.

Journal of Chemical Information and Modeling, 1, 1689-1699.

https://doi.org/10.1017/CBO9781107415324.004

Hughes, F. P. (2010). Children, play, and development (4th editio). Sage

Publications.

Indrayana, B. (2017). Pengaruh Permainan Tradisional Terhadap Pengembangan

Gerak Dasar Siswa SD Negeri 196/1V Kota Baru Kota Jambi. Journal Physical Education, Health and Recreation, 2(1), 28.

https://doi.org/10.24114/pjkr.v2i1.7837

Jihad, A., \& Haris, A. (2012). Evaluasi Pembelajaran. Multi Presindo.

Moleong, L. (2011). Metodologi Penelitian Kualitatif. Remaja Rosdakarya.

Ripai, I., \& Nana Sutarna. (2019). Analisis Kemampuan Pemecahan Masalah Menggunakan Model Pembelajaran Problem Base Learning. Literasi Pendidikan Karakter Berwawasan Kearifan Lokal Pada Era Revolusi Industri 4.0”, 4(2017), 31-44.

Rosdiani, D. (2012). Model Pembelajaran Langsung Dalam Pendidikan Jasmani dan Kesehatan. Alfabeta.

Saifullah. (2010). Metodologi Penelitian. UIN Malang.

Sugiyono. (2014). Metode Penelitian Pendidikan (Pendekatan Kuantitatif Kualitatif dan $R \& D)$. Alfabeta.

Sugiyono. (2017). Metode Penelitian dan Pengembangan Research and Development. Alfabeta.

Suharnoko, F., \& Firmansyah, G. (2018). Pengembangan Model Pembelajaran Melompat Melalui Permainan Lompat Cermin untuk Siswa Sekolah Dasar. Jurnal SPORTIF : Jurnal Penelitian Pembelajaran, 4(2), 145. 
https://doi.org/10.29407/js_unpgri.v4i2.12169

Suprayitno. (2014). Peran Permainan Tradisional Dalam Membantu Pertumbuhan

Dan Perkembangan Gerak Anak Secara Menyeluruh. Jurnal Ilmu Keolahragaan, 13(2), 38-44.

Usra, M. (2012). Nilai-Nilai Olahraga dan Pendidikan Jasmani dalam Pembentukan Karakter Bangsa. Jurnal IImu Olahraga Dan Kesehatan, 2.

Wibowo, Y. G., \& Indrayana, B. (2019). Sport: A review of healthy lifestyle in the world. Indonesian Journal of Sport Science and Coaching, 1(1), 30-34. 